\title{
Divulgando astronomia no ensino fundamental por meio de um planetário móvel
}

João Paulo da Silva Melo joaopaulo 15@hotmail.com orcid.org/0000-0001-5213-5183 (UFSJ), São João del-Rei, Minas Gerais, Brasil

Samuel William de Paulo Oliveira sw.oliveira55@gmail.com

orcid.org/0000-0002-9407-7150

Universidade Federal de São João del-Rei (UFSJ), São João del-Rei, Minas Gerais, Brasil

Alessandro Damásio Trani

\section{Gomes}

alessandrogomes@ufsj.edu.br orcid.org/0000-0001-9095-5270 Universidade Federal de São João del-Rei (UFSJ), São João del-Rei, Minas Gerais,
Brasil

Fernando Otávio Coelho focoelho@ufsj.edu.br orcid.org/0000-0002-7069-8905 Universidade Federal de São João del-Re (UFSJ), São João del-Rei, Minas Gerais, Brasi

\section{RESUMO}

Neste trabalho, descreve-se atividades desenvolvidas no âmbito de um projeto de extensão destinado à divulgação científica em Astronomia. Analisa-se também os resultados de uma pesquisa que discute o contato e o conhecimento prévio em Astronomia de 154 alunos do quinto e sexto ano do ensino fundamental de escolas da rede pública de cidades da região do Campo das Vertentes de Minas Gerais, e busca identificar manifestações espontâneas de aprendizagem decorrentes das sessões de cúpula realizadas com um planetário móvel. Os participantes responderam a questionários antes e um dia após a sessão de cúpula. Os resultados sugerem que a atividade extensionista realizada foi bem-sucedida, tendo um índice de aprovação superior a $98 \%$ e com mais de $93 \%$ dos participantes conseguindo mencionar, corretamente, algo que avaliaram ter aprendido com a atividade desenvolvida. Com base nos resultados obtidos, são discutidas as implicações educacionais e propostas novas possibilidades de pesquisa na área.

PALAVRAS-CHAVE: Planetário. Extensão universitária. Educação não formal. 


\section{INTRODUÇÃO}

O homem tem observado o céu desde a pré-história, por motivações místicas e/ou sócio-organizacionais. $O$ ato de olhar para o céu também pode nos colocar diante dos maiores questionamentos que dizem respeito a quem somos, de onde viemos e para onde vamos. Tal prática, além de revelar a curiosidade humana, deu início à Astronomia, uma das ciências mais antigas desenvolvidas pelo homem, que foi responsável pela revolução científica dos séculos XVI e XVII.

Mesmo as pessoas que nunca tiveram contato formal com a Astronomia, já olharam para o céu durante um dia ensolarado ou uma noite com céu limpo, e admiraram as efemérides celestes e a imensidão do cosmos (MILONE et al., 2003).

Apesar de ser uma ciência muito antiga, com contribuições fundamentais para a evolução da humanidade, os estudos relacionados ao ensino de Astronomia são relativamente recentes (BAILEY; SLATER, 2003; LELLIOTT; ROLLNICK, 2010). Com o lançamento do Sputnik em 1957, estudos relacionados ao ensino de Astronomia ganharam força. Os países desenvolvidos reestruturaram seus programas educacionais de Ciências, ampliando os conceitos científicos levados à comunidade em geral, para não ficarem atrasados na corrida espacial. Para este propósito foram utilizados a riqueza visual, o poder interdisciplinar e a atratividade da Astronomia. Esse fato contribuiu para estimular a pesquisa na área (TÜRK; KALKAN, 2015).

Assim como Gomes e Zanon (2019, p. 151), defende-se nessa pesquisa a importância de que tópicos em Astronomia sejam devidamente abordados com as crianças ainda no ensino fundamental, contribuindo para "despertar a contemplação pela natureza e a consciência de que o ser humano está inserido no tempo e no espaço, no mundo cósmico, trazendo a motivação necessária para a busca pelo conhecimento científico".

Infelizmente, no Brasil, apesar de prevista nos documentos oficiais que regulam a educação básica, a Astronomia não é devidamente abordada, sendo vista de forma fragmentada e episódica em disciplinas como Ciências no ensino fundamental e Física no ensino médio.

Apesar de benefícios evidentes do ensino da Astronomia apontados por Caniato (1974),

parece haver um descaso quanto à abordagem deste tema na educação brasileira. Uma análise sobre a história mostra como a astronomia sofreu uma gradual dispersão e quase desaparecimento dos currículos escolares. Nem mesmo o professor brasileiro do Ensino Fundamental e Médio, na maioria dos casos, aprende conteúdos de astronomia durante a sua formação na faculdade. Como consequência, os professores, em geral, optam por duas alternativas: preferem não ensinar astronomia ou buscam outras fontes de informações. Porém, há carência de fontes seguras sobre astronomia, pois até mesmo livros didáticos apresentam erros conceituais. A mídia é escassa em documentários sobre este tema, e muitas vezes prefere exagerar no sensacionalismo em notícias que envolvem assuntos sobre o espaço sideral (LANGHI, 2009, p. 9).

Espaços não formais de educação podem ajudar a suprir, em parte, a carência 
área do conhecimento humano que encanta e desperta o interesse de grande parte da população.

O termo "espaço não formal" tem sido utilizado por educadores, pesquisadores na área de Educação e profissionais que trabalham com divulgação científica para descrever lugares, diferentes da escola, onde é possível desenvolver atividades educativas. Por haver divergências conceituais acerca do termo, considera-se, assim como Elias, Amaral e Araújo (2007), que a educação não formal representa um amplo conjunto de atividades extraclasse que possuem metodologias flexíveis, nas quais o ensino ocorre de forma interativa, conduzindo o aluno a participar ativamente do processo de construção de seu conhecimento.

O planetário é um exemplo de espaço não formal de educação destinado, principalmente, ao ensino de Astronomia. Trata-se de um ambiente que conta com uma cúpula semiesférica, onde são projetados o céu e os corpos celestes com projetores optomecânicos ou digitais de última geração. O programa de simulação dos movimentos dos corpos celestes permite avançar e retroceder no tempo e mudar o ponto de observação para qualquer corpo do Sistema Solar, o que permite a visualização de fenômenos como eclipses e chuvas de meteoros de vários pontos de vista, facilitando sua compreensão.

Marandino e colaboradores (2004) consideram que as pesquisas na área de ensino de Ciências que abordam a divulgação científica em espaços não formais de educação são escassas. São ainda mais raros os estudos nacionais diretamente relacionados ao ensino de Astronomia em espaços como planetários, observatórios e clubes de Astronomia (LANGHI; NARDI, 2009; SIEMSEN; LORENZETTI, 2017).

Este trabalho descreve as atividades desenvolvidas no âmbito de um projeto de extensão destinado à divulgação científica em Astronomia. Analisa-se também os resultados de uma pesquisa que discute o contato e o conhecimento prévio em Astronomia de 154 alunos do quinto e sexto ano do ensino fundamental de escolas da rede pública de cidades da região do Campo das Vertentes de Minas Gerais e busca identificar manifestações espontâneas de aprendizagem decorrentes das sessões de cúpula realizadas com um planetário móvel.

\section{O ENSINO DE ASTRONOMIA, EDUCAÇÃO NÃO FORMAL E PLANETÁRIOS}

A Base Nacional Comum Curricular (BNCC), documento de caráter normativo que define o conjunto orgânico e progressivo de aprendizagens essenciais que todos os alunos devem desenvolver ao longo da Educação Básica, propõe a organização dos currículos de Ciências em três unidades temáticas que se repetem ao longo de todo o ensino fundamental (BRASIL, 2018b). São elas: "Matéria e energia"; "Vida e evolução"; e finalmente, "Terra e Universo", na qual "busca-se a compreensão de características da Terra, do Sol, da Lua e de outros corpos celestes - suas dimensões, composição, localizações, movimentos e forças que atuam entre eles" (p. 328).

Segundo a BNCC, os alunos começam a se apropriar de explicações científicas envolvendo as temáticas "Vida e Evolução" e "Terra e Universo" no ensino fundamental, também procedendo análises do sistema solar e dos movimentos da Terra em relação ao Sol e à Lua. No ensino médio, torna-se possível unificar essas 
duas temáticas, levando o aluno a uma compreensão mais ampla dos processos a elas relacionados.

Ainda segundo a BNCC, uma das três competências específicas que a área de Ciências da Natureza e suas Tecnologias deve garantir, está diretamente relacionada a conteúdos ligados à Astronomia: “Construir e utilizar interpretações sobre a dinâmica da Vida, da Terra e do Cosmos para elaborar argumentos, realizar previsões sobre o funcionamento e a evolução dos seres vivos e do Universo, e fundamentar decisões éticas e responsáveis" (BRASIL, 2018b, p. 539).

Diversos trabalhos abordam a distância entre o que é proposto nos documentos oficiais e a realidade do insucesso do ensino de Astronomia nas escolas. Os motivos para isso são discutidos em diversos artigos (CARVALHO et al., 2016; LANGHI; NARDI, 2009; LANGHI, 2011).

Tendo em vista essa realidade, espaços de educação não formais como planetários, observatórios e centro de Ciências podem desempenhar um importante papel na promoção adequada do ensino e na divulgação científica em Astronomia. Existe hoje um consenso em relação à importância e à necessidade de se elaborar políticas e estratégias pedagógicas de divulgação da Ciência que efetivamente auxiliem na compreensão do conhecimento científico, por meio de experiências fora da escola (MARANDINO et al., 2004).

Bueno (2009, p.162) considera que a divulgação científica compreende a "utilização de recursos, técnicas, processos e produtos (veículos ou canais) para a veiculação de informações científicas, tecnológicas ou associadas a inovações ao público leigo". Para Loureiro (2003), a divulgação científica constitui-se no emprego de técnicas de recodificação de linguagem da informação científica e tecnológica objetivando atingir o público em geral e utilizando diferentes meios de comunicação.

As formas de divulgação científica evoluíram, acompanhando a própria evolução das Ciências e dos recursos tecnológicos, gerando, assim, uma grande multiplicidade de formas e meios de popularização. Centros de ciências, bibliotecas, laboratórios, museus, exposições, planetários, observatórios, centros de tecnologia, zoológicos, jardins botânicos, dentre outros, são exemplos de ambientes que podem ser considerados como espaços não formais de educação.

Para Vieira, Bianconi e Dias (2005), espaços como museus de ciências, observatórios, clubes de astronomia e planetários "oferecem a oportunidade de suprir, ao menos em parte, algumas das carências da escola como a falta de laboratórios, recursos audiovisuais, entre outros, conhecidos por estimular o aprendizado" (p. 21). Tais espaços apresentam-se como recursos para auxiliar na apropriação do conhecimento como um bem cultural, por meio de uma abordagem interessante, possibilitando a utilização de métodos diferenciados de ensino, atrelados às atividades que proporcionem informação acessível e de qualidade.

Diversas pesquisas sobre a aprendizagem têm evidenciado o potencial destes espaços, indicando que tais ambientes despertam o interesse e a curiosidade, motivam, socializam e estimulam os alunos, sendo esses elementos fundamentais nos processos de ensino e aprendizagem (FREITAS, GERMANO; AROCA, 2013; 
Os planetários são exemplos de espaços não formais de educação. Segundo Almeida e colaboradores (2017, p. 71),

\begin{abstract}
o termo planetário diz respeito ao ambiente no qual, com equipamentos de projeção, no centro de uma cúpula abobadada, som ambiente e até mesmo sistemas mecânicos de movimento, é apresentada a imagem do céu de qualquer ponto do Sistema Solar, em qualquer tempo e de qualquer época, passada ou futura, bem como as trajetórias dos corpos celestes ao longo do tempo, sendo possível inclusive a alteração na velocidade dos movimentos para oferecer a melhor visualização de um fenômeno celeste específico. Atualmente, além de simulações da esfera celeste, podem ser apresentados filmes ou outros conteúdos multimídia sobre diversos assuntos científicos.
\end{abstract}

A cúpula configura-se, assim, como um ambiente tridimensional de ilusão e imersão. Devido a esse fato, os planetários têm a capacidade de afetar psicologicamente o senso de realidade do visitante, fazendo com que eles mergulhem totalmente em uma envolvente experiência audiovisual (LANTZ, 2011). Lantz denomina essa experiência como "imersão sensorial" e sugere que o valor educacional resultante pode ser tanto cognitivo quanto afetivo. Heimlich e colaboradores (2010) apontam que o interesse do público no tema abordado é maior em planetários com projeção em cúpulas, sendo este um modo estimulante de apresentar informações científicas, seja de natureza astronômica ou não.

Os planetários são, portanto, ambientes adequados para pessoas de todas as idades aprenderem conceitos básicos sobre Astronomia. Muitos desses conceitos, como o movimento aparente do Sol, as fases lunares e as posições dos objetos no céu, são conceitos-chave que se espera que os estudantes conheçam no final da educação básica. Muitos desses tópicos são difíceis de serem visualizados, porque acontecem lentamente ao longo de horas, dias ou até mesmo meses. Isso contribui para o desenvolvimento, por parte de crianças e adultos, de ideais inadequadas ou idiossincráticas sobre tais fenômenos (LANGHI, 2011; SLATER, MORRIS; MCKINNON, 2018). Como o planetário pode acelerar os movimentos dos corpos celestes, eles se tornam mais concretos e visíveis. Os planetários oferecem um ambiente muito útil e imersivo para o ensino de conceitos de Astronomia por meio da simulação desses fenômenos.

Planetários móveis objetivam a divulgação científica, possibilitam a conexão de pessoas à Ciência, dão às Ciências, em especial à Astronomia, presença na comunidade e oferecem às pessoas de todas as idades e classe social a oportunidade de fazerem perguntas, discutir e explorar conceitos científicos. Assim, necessariamente, um planetário móvel é interativo e busca a comunicação com um público diversificado. Na aprendizagem alcançada em um planetário móvel, o contexto social por ele proporcionado desempenha um importante papel, e configura-se como oportunidade para o crescimento e desenvolvimento pessoal, assim como ampliação da visão de mundo.

Foram identificados poucos trabalhos com relatos de resultados empíricos decorrentes de projetos de extensão, com alunos ou com público em geral, tendo um planetário como principal meio de ensino.

Romanzini e Ber (2012), por exemplo, realizam uma síntese das atividades projetadas e desenvolvidas como parte de um projeto de extensão desenvolvido no Planetário de Londrina, visando à popularização da Astronomia e ciências afins, mas não apresentam os resultados destas atividades. 
De Maman e colaboradores (2015), apresentam resultados preliminares do projeto de extensão "Percorrendo o Vale, desvendando o céu", baseado em um planetário móvel, que tem por objetivo estimular os participantes a aperfeiçoarem seu conhecimento e ampliarem sua cultura científica em Astronomia.

\section{O PROJETO DE EXTENSÃO}

Este trabalho insere-se em um projeto de extensão denominado "Planetário móvel: a UFSJ leva o Universo até você", que é desenvolvido há três anos. O objetivo do projeto é promover a divulgação científica por meio da Astronomia. Busca-se oferecer às comunidades, tanto local, quanto das cidades e municípios da região do campo das Vertentes, a oportunidade de vivenciar a experiência científica, maravilhar-se com a criatividade e beleza da Ciência e ter uma melhor compreensão sobre o cosmos, a natureza e a tecnologia.

O público atendido pelo projeto de extensão, até dezembro/2019, foi de 10.000 pessoas, sendo realizadas 500 sessões de cúpula. Dessas, 400 sessões foram destinadas às escolas da educação básica, públicas e particulares de treze cidades da região do Campo das Vertentes, em Minas Gerais. Cerca de 8.000 alunos de 30 escolas puderam participar das atividades desenvolvidas. Também foram realizadas 100 sessões regulares, abertas ao público em geral, que contaram com cerca de 2.000 visitantes.

O planetário utilizado no projeto consta de domo inflável com revestimento polimérico de duas camadas (capa principal e capa para projeção interna), fabricado por meio de costura, com 6 metros de diâmetro e 4,0 metros de altura, com capacidade para até 25 pessoas por sessão (Figura 1). A operação do planetário é feita por meio de um sistema digital para projeção hemisférica no interior em cúpulas semiesféricas, com projetor único, com campo de visão de $180^{\circ} \times 360^{\circ}$, sem utilização de espelhos e matrizes de projeção, mas por meio de uma única lente fixa no sistema que lança a imagem para uma meia-esfera, sem deformação.

O equipamento é desenhado para atender às necessidades pedagógicas requeridas pelos brasileiros que ainda se veem distantes destes ambientes em funcionamento no país, facilitando o acesso à valorosa vivência científica proporcionada por tais instalações, democratizando e popularizando, assim, o conhecimento científico, sendo adequado para o projeto de extensão em questão.

A Resolução MEC/CNE/CES № 7/2018, que estabelece as Diretrizes para a Extensão na Educação Superior Brasileira, em seu Art. 3, considera a extensão uma

\footnotetext{
atividade que se integra à matriz curricular e à organização da pesquisa, constituindo-se em processo interdisciplinar, político educacional, cultural, científico, tecnológico, que promove a interação transformadora entre as instituições de ensino superior e os outros setores da sociedade, por meio da produção e da aplicação do conhecimento, em articulação permanente com o ensino e a pesquisa (BRASIL, 2018a, p. 49).
} 


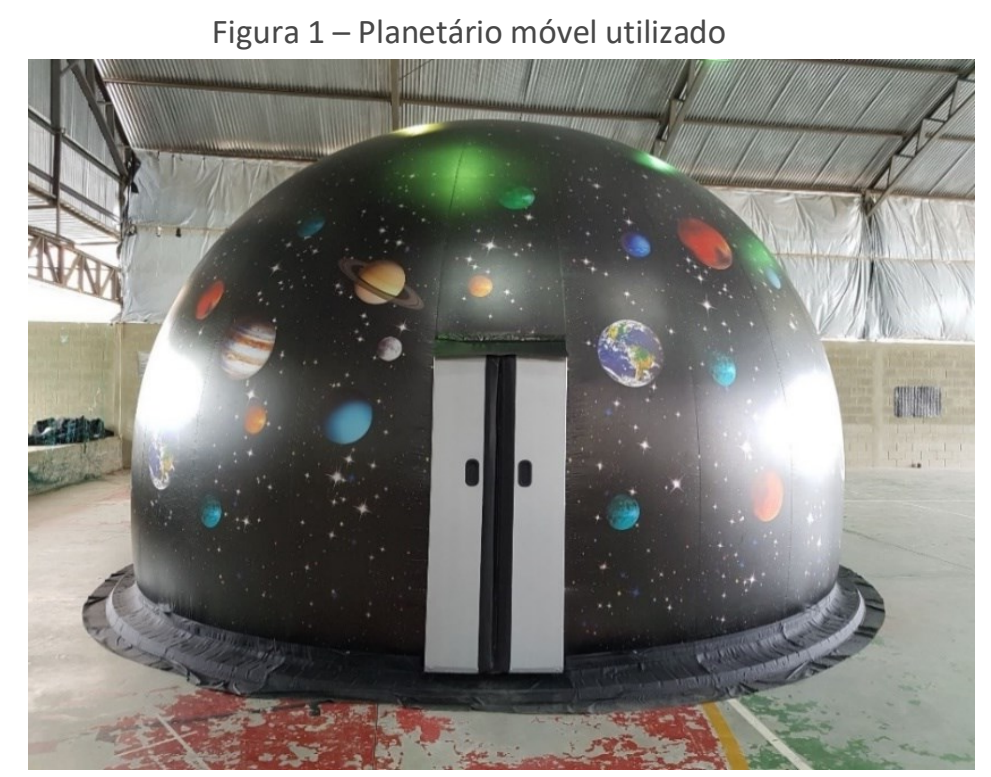

Fonte: Autoria própria (2019).

Compartilha-se com Costa, Santos e Grinspun (2009) as concepções do fazer extensionista, que inclui a possibilidade de construção da interlocução da práxis pedagógica e intelectual com a sociedade. Visto dessa forma, as propostas e produtos da extensão mantém e se produzem em uma dinâmica de aprendizagem reflexiva, mútua e autônoma, por meio de um vínculo entre sociedade e universidade.

Síveres (2010) propõe que a universidade seja considerada como uma "ambiência de aprendizagem". Segundo o autor,

na caracterização da universidade como uma ambiência de aprendizagem, a extensão universitária tem um papel importante a desempenhar, na medida em que a sua relação com os saberes potencializa a autonomia dos sujeitos, a emancipação das comunidades e a soberania da população. Dessa forma, a extensão constitui-se numa atmosfera propícia para acolher, cuidar e desenvolver conhecimentos que, por sua vez, estão vinculados ao processo educativo (p.10).

Síveres ainda considera a extensão universitária como um "percurso aprendente". Para ele, a extensão,

para além de contribuir com a identidade institucional e com a finalidade educacional, a mesma pode ser compreendida como um processo aprendente, objetivando desencadear um percurso que, junto com o ensino e a pesquisa, postulem uma aprendizagem significativa para os sujeitos envolvidos na reflexão e na prática acadêmica (SÍVERES, 2010, p.12).

O objetivo das atividades extensionistas é, portanto, a constituição de um fluxo que estabeleça a troca de saberes acadêmico e popular, tendo como consequência a produção do conhecimento resultante do confronto com as realidades regionais e nacionais, a democratização do conhecimento acadêmico e a participação efetiva da comunidade na atuação da universidade (MORAES; WISNIEWSKI; ROCHA, 2014). 


\section{ASPECTOS METODOLÓGICOS}

Como já mencionado, o projeto de extensão "Planetário móvel: a UFSJ leva o Universo até você" já desenvolveu atividades extensionistas de divulgação científica em Astronomia para cerca de 10.000 pessoas. Destas, foi selecionada uma amostra condizente com o objetivo almejado pela pesquisa.

\section{Participantes}

Os participantes desta pesquisa são 154 alunos do quinto e sexto ano do ensino fundamental da rede pública de três cidades próximas a São João del-Rei, com faixa etária entre 10 e 13 anos.

Por se tratar de um evento pedagógico promovido pela escola, os pais e/ou responsáveis das crianças já haviam sido informados sobre a participação dos alunos nas atividades do planetário. Para que os dados gerados pudessem ser utilizados para fins de pesquisa, foram solicitadas autorizações à diretora da escola e às professoras das turmas envolvidas, assegurando o anonimato e a integridade moral dos participantes.

\section{A atividade desenvolvida}

O planetário móvel foi instalado nas quadras das escolas participantes e permaneceu, em média, dois dias em cada escola. Antes da visita do planetário à escola, foi organizado um cronograma para que todas as turmas pudessem participar das sessões de cúpula.

As sessões de cúpula tiveram uma duração de aproximadamente 45 minutos. Na primeira parte, por meio de uma abordagem dialógica e problematizadora, era feita uma apresentação interativa sobre os movimentos aparentes do Sol e da Lua, simulações de anoitecer e amanhecer, a identificação dos planetas visíveis da Terra a olho desarmado e de algumas constelações mais tradicionais. Lopes (1991, p.42) afirma que essa abordagem "utiliza o diálogo entre professor e aluno para estabelecer uma relação de intercâmbio de conhecimentos e experiências". Segundo Santos, Machado e Sobral (2016, p. 208), "a dialogicidade se estabelece entre os sujeitos envolvidos sobre a realidade que os mediatizam. Com o processo educativo dialógico e problematizador está subjacente a ideia de transformação para uma sociedade mais humanizada", mais inclusiva, que compreende as diferenças e que ofereça oportunidades de aprendizagem a todos.

Em seguida, era feita a exibição do filme "Os filhos do Sol". O filme, em mídia fulldome, extensão .avi, é exclusivo para projeção em planetários digitais e foi produzido pela Projekt Design e Hiperlab Equipamentos Científicos Ltda e tem duração de 22 minutos. Nele, apresentam-se os planetas do Sistema Solar e um pouco sobre a composição e características físicas de cada um deles. O filme começa apresentando o céu visto da Terra e mostra que cinco planetas podem ser vistos a olho desarmado. Após apresentar a esfera celeste, o espectador é levado a conhecer de perto as características do Sol, visitar os planetas, alguns de seus satélites naturais e sobrevoar algumas superfícies planetárias. Ao final, simula-se uma "carona" em um cometa para retornar à Terra, possibilitando uma visão mais 
detalhada do nosso planeta visto do espaço. Assim, os recursos visuais oferecidos pelo planetário permitem, por exemplo, que seja feita uma rica discussão a respeito de aspectos geológicos dos diferentes componentes do Sistema Solar e do seu processo de formação, bem como a visualização da ordem de grandeza das distâncias e do tamanho relativo dos corpos celestes, em especial quando comparados com o Sol.

\section{Instrumentos e procedimentos de pesquisa}

Um questionário exploratório inicial (figura 2), composto por 3 questões, foi elaborado para identificar o contato, as concepções prévias e as associações que os alunos participantes fazem com Astronomia.

O questionário foi aplicado aos alunos antes da chegada do planetário à escola, sem qualquer referência a ele e aos conteúdos que seriam abordados pela atividade ainda a ser desenvolvida.

Figura 2-Questionário inicial

Nome__ Escreva as três primeiras palavras que vêm na sua cabeça quando você pensa em
ASTRONOMIA.
2) Você já olhou para o céu durante a noite?
( ) SIM
Se você respondeu SIM, o que você já observou no céu?
3) Você já assistiu algum filme ou programa de televisão que falou sobre Astronomia?
( ) SIM

Fonte: Autoria própria (2019).

Com o objetivo de avaliar a atividade desenvolvida, se ela supriu as expectativas dos participantes e buscando identificar relatos espontâneos de aprendizagem, foi utilizado um questionário final (figura 3), preenchido no dia seguinte às atividades.

Foram realizadas oito sessões de cúpula, com cerca de 14 a 25 alunos por sessão, devidamente acompanhados por seus professores. Os bolsistas de extensão foram os responsáveis pela condução das atividades, operando o 
projetor, organizando a entrada e saída dos alunos do planetário e fazendo a apresentação interativa.

Figura 3-Questionário final
Nome: Idade
1) Você gostou da atividade desenvolvida com o planetário?
( ) SIM
( ) NÃO
2) Escreva o que você mais gostou.
3) Teve alguma coisa que você não gostou?
4) Escreva alguma coisa que você aprendeu com a atividade. Turma:

Fonte: Autoria própria (2019).

\section{RESULTADOS E DISCUSSÃO}

Durante a exposição interativa sobre o Sol, a Lua, os planetas e as constelações, houve uma boa participação dos estudantes com vários comentários e perguntas de variados níveis, estabelecendo-se entre os alunos e os bolsistas de extensão uma interação muito produtiva. À guisa de exemplificação, apresentamos algumas das perguntas feitas pelos estudantes durante essa etapa:

$$
\begin{array}{r}
\text { "Qual a diferença entre fases da Lua e eclipse?" } \\
\text { "Por que não temos eclipse todos os meses?" } \\
\text { "A fase da Lua é a mesma durante uma noite seguida aqui no Brasil e no } \\
\text { Japão?" } \\
\text { "Tem noite que não é possível ver nenhum planeta no céu?" } \\
\text { "A Lua sempre aparece no céu no mesmo horário?" }
\end{array}
$$

Os alunos perceberam que tinham a liberdade de expor seus questionamentos e pensamentos e os bolsistas demonstraram tranquilidade e domínio do conteúdo para discutir, dirimir as dúvidas e responder às perguntas. Arrigone e Mutti (2011) defendem que perguntas e intervenções feitas pelos estudantes fornecem indícios sobre o engajamento e o interesse deles durante as atividades. Portanto, pode-se inferir que os alunos, de forma geral, se mostraram motivados e interessados durante a sessão no planetário. Para Specht, Ribeiro e Ramos (2017), a utilização da pergunta elaborada pelos sujeitos é um importante recurso de incentivo à aprendizagem dos estudantes. Quando o estudante elabora espontaneamente uma pergunta ele demonstra interesse pelo conteúdo que está aprendendo, trazendo para a discussão os seus interesses e suas dúvidas.

Durante a exibição do filme, os alunos permaneceram em silêncio, demonstrando atenção e interesse pelo conteúdo abordado. Em alguns momentos pode-se ouvir expressões de surpresa e fascínio coletivo como "Nossa" ou "Nuh", quando eles percebiam a ordem de grandeza de determinados eventos. Após a 
sessão, os alunos se mostraram muito entusiasmados e interessados em tudo que foi exibido durante a sessão de cúpula.

A análise das respostas dos alunos à primeira questão do questionário inicial revelou um universo de 442 palavras, sendo 403 palavras simples e 14 expressões com mais de uma palavra. Houve também 20 lacunas sem resposta. Os participantes utilizaram um total de 85 palavras diferentes para responder a questão. Para se perceber a riqueza e a diversidade das palavras utilizadas, construiu-se uma nuvem de palavras com aquelas que foram utilizadas, pelo menos, duas vezes (figura 4).

Figura 4 - Nuvem de palavras que representa a frequência da ocorrência dos termos relacionados à Astronomia escritos pelos alunos

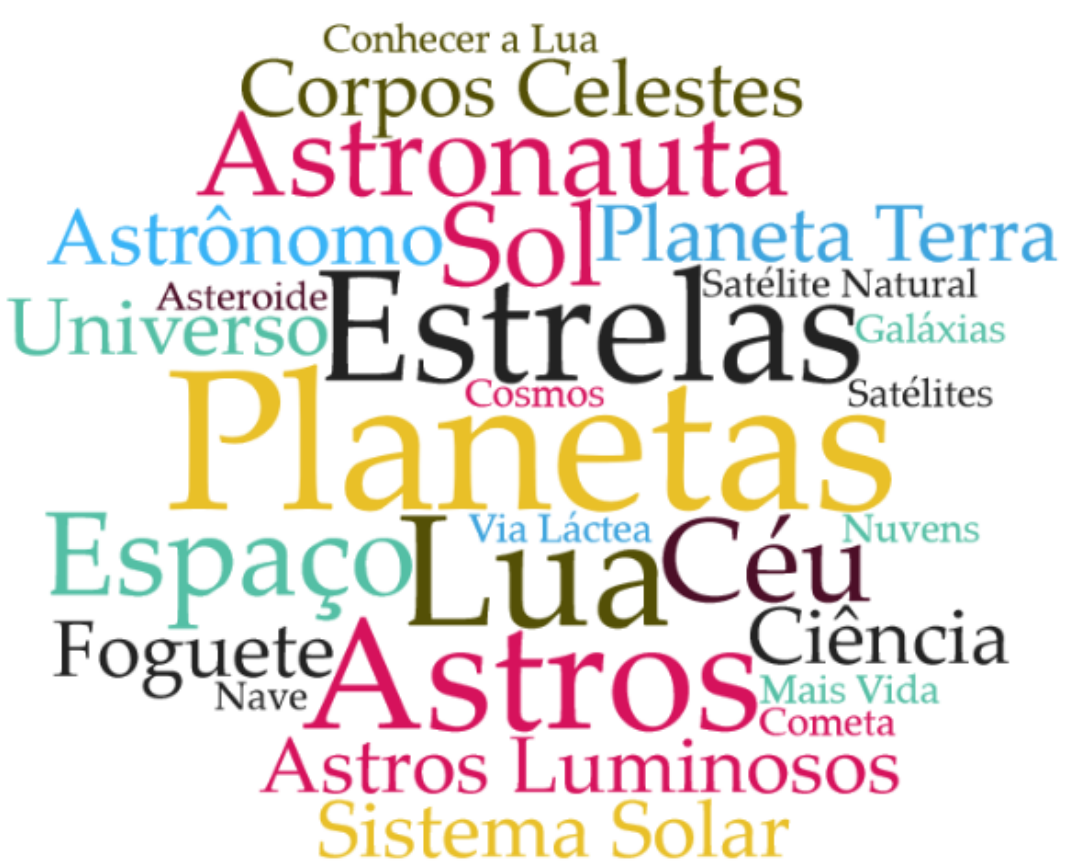

Fonte: Autoria própria (2020).

As 10 palavras mais citadas contabilizam 310 ocorrências e são termos intimamente ligados à Astronomia, bem como algumas expressões identificadas: "Conhecer a Lua" ou "Vida em Marte". Apenas 15 palavras e/ou expressões utilizadas pelos alunos como "Economia", "Eólica"; "Mergulho"; "Thanos" ou "Ciência que estuda" não podem ser associadas diretamente à Astronomia. Isso indica que a grande maioria dos alunos que participaram da atividade possuem algum conhecimento prévio ou fazem ideia do que seja Astronomia ou o que ela estuda.

Quando questionados sobre já terem olhado para o céu durante a noite (questão 2 do questionário inicial), 147 alunos marcaram que sim e outros 7, não. Em caso afirmativo foi solicitado que escrevessem o que observaram e a maior parte dos alunos disseram ter observado as estrelas (122 ocorrências), Lua (88 ocorrências) e planetas (10 ocorrências). Foi possível identificar respostas mais elaboradas como o nome de determinadas constelações, as fases da Lua, e expressões como "Cruzeiro do Sul”, "Estrela Cadente" e "Via Láctea”, evidenciando 
que alguns alunos, dentre os participantes, possuem maior familiaridade com observações do céu noturno.

Para investigarmos melhor sobre o contato dos alunos com temas e assuntos relacionados à Astronomia, perguntamos se os alunos já tiveram oportunidade de assistir algum filme ou programa de televisão no qual abordasse Astronomia. Dos 154 participantes, 32 responderam afirmativamente. Neste caso, era solicitado que eles escrevessem qual era o filme ou programa. A tabela 1 mostra as citações e suas respectivas ocorrências.

Tabela 1 - Filmes, Animação, Seriados, Documentários e Programas de TV citados

\begin{tabular}{ccc} 
Programa & Tipo & Ocorrência \\
Dr. Who & Seriado & 4 \\
\hline A Culpa é das Estrelas & Filme & 3 \\
\hline National Geographic & Canal de documentários & 2 \\
\hline Star Wars & Filme & 2 \\
\hline Como Será? & Programa de TV & 1 \\
\hline Cosmos & Documentário & 1 \\
\hline Depois da Terra & Filme & 1 \\
\hline Futurama & Animação & 1 \\
\hline Jornal Nacional & Programa Jornalístico & 1 \\
\hline O Meteoro & Filme & 1 \\
\hline O Show da Luna & Desenho Animado & 1 \\
\hline Planeta Extremo & Seriado/Documentário & 1 \\
\hline Segredos da NASA & Seriado & 1 \\
\hline Toy Story & Filme de Animação & 1 \\
\hline
\end{tabular}

Fonte: Autoria própria (2020).

Dois alunos relataram ter visto o tema ser tratado em programas que falam sobre o Espaço e em programas que apresentam o funcionamento e as particularidades do Sistema Solar. Outros dois escreveram que viram em programas chamados "Astros luminosos" e "Falando sobre o Espaço" que não foram identificados como existentes. E os outros 7 disseram não se lembrar o nome do programa.

A análise dos tipos de programas presentes na tabela 1 permite verificar que os alunos participantes desta pesquisa, em sua maioria, tem contato com assuntos relacionados à Astronomia por meio de programas que não objetivam à divulgação científica de qualidade e, portanto, não possuem o compromisso de transmitir informações científicas com o devido rigor, o que pode gerar, em muitos casos, o desenvolvimento ou o reforço de concepções inadequadas sobre diversos fenômenos celestes. Por outro lado, nota-se a ocorrência de programas como "Cosmos", que tem o compromisso de divulgar conteúdos de Astronomia de qualidade e o canal de TV National Geographic, que apesar de ser uma exclusividade da TV por assinatura, e por essa razão não ser acessível a muitas 
pessoas, tem em sua programação vários seriados e documentários com informações adequadas.

As respostas dos participantes as duas primeiras perguntas revelam um aspecto a ser ressaltado. Cerca de $5 \%$ responderam que nunca olharam para o céu durante a noite e quase $80 \%$ responderam que nunca assistiram um filme ou programa de televisão que abordasse algum conteúdo de Astronomia. Tais resultados, corroboram a posição de Soler e Leite (2012) ao argumentarem que, considerar a Astronomia um assunto que desperta muito o interesse e curiosidade dos alunos faz parte "do senso comum do ato de se ensinar e divulgar Astronomia" (p. 377) e que não há tanto respaldo assim, por meio de pesquisas empíricas, sobre essa afirmação.

No dia seguinte à atividade no planetário, os alunos responderam ao questionário final. Na questão 1 foi perguntado se os participantes gostaram da atividade realizada. A aprovação superou os $98 \%$, com 152 participantes marcando que gostaram da atividade.

$\mathrm{Na}$ questão 2, os alunos responderam sobre o que mais gostaram. Após a leitura das respostas dos alunos, foi possível categorizá-las de acordo com o aspecto mais destacado. A tabela 2 sintetiza os aspectos presentes nas respostas mais recorrentes. A soma das ocorrências pode ultrapassar o número de respondentes, pois em uma mesma resposta, pôde ser identificado mais de um aspecto.

Tabela 2 - Aspectos que os alunos mais gostaram na atividade

\begin{tabular}{cc} 
Aspecto & Ocorrência \\
\hline Planetas & 92 \\
\hline Tudo & 29 \\
\hline Da viagem & 20 \\
\hline Sol & 15 \\
\hline História dos Planetas & 14 \\
\hline Lua & 7 \\
\hline Estrelas & 6
\end{tabular}

Fonte: Autoria própria (2020).

Boa parte dos alunos (59\%) citou os planetas como aspecto que eles mais gostaram. Realmente, a ênfase do filme apresentado são os planetas do Sistema Solar. Portanto, esse resultado era, de certa forma, esperado. Muitos alunos citaram planetas e seus aspectos específicos. Um dos mais citados foi o nosso, o planeta Terra. Também foram bastante citados Saturno, por causa de seus belos anéis e Júpiter, por ser o maior planeta do Sistema Solar. As respostas abaixo representam um pouco do espectro de respostas obtidas para essa questão:

"Eu gostei das tempestades em Júpiter."

"Eu gostei dos planetas e das estrelas."

"Gostei de aprender sobre os planetas." "A parte que a gente conheceu nosso planeta." 
Algumas respostas como: "De ver os planetas como se eu estivesse lá"; "Da parte em que o Sol estava se aproximando de nós. Parecia que ele estava caindo"; "Eu gostei de tudo, porque parecia que a gente estava no Espaço.", mostram que os recursos audiovisuais do planetário foram capazes de prender a atenção dos alunos, causando-lhes um grande encantamento e fazendo com que os participantes permanecessem atentos a todos os detalhes.

Os planetários têm o potencial de mediar a aprendizagem, fornecendo experiências sensoriais incomuns e intensas que focam a atenção do público. Ambientes imersivos, como os planetários, dão aos participantes uma sensação de pertença, que se correlacionam positivamente com a atenção, o que pode resultar em níveis mais elevados de aprendizagens. A pesquisa educacional, incluindo estudos conduzidos em planetários, indica que experiências ativas para o público são mais efetivas na promoção dos tipos de engajamento que produzem mudanças afetivas e cognitivas (DONOVAN; BRANSFORD, 2005).

$\mathrm{Na}$ terceira questão foi perguntado se teve algo durante a atividade que os alunos não gostaram. Onze alunos responderam afirmativamente. Cinco citaram não terem gostado do excesso de claridade quando foi apresentado o Sol, pois causava algum desconforto visual. Dois alunos alegaram terem ficado tontos, um aluno reclamou de ter que ficar deitado no chão durante a sessão e outros dois alunos mencionaram passagens específicas do filme que não gostaram. Apenas um aluno alegou, sem justificar, que não gostou de nada.

Por fim, foi solicitado que escrevessem algo que tenham aprendido com a atividade desenvolvida. Dos 154 participantes, 147 escreveram alguma resposta. A tabela 3 apresenta a compilação dos aspectos mais lembrados pelos alunos. A soma das ocorrências pode ultrapassar o número de respondentes, pois em uma mesma resposta, pôde ser identificado mais de um aspecto.

Tabela 3 - Aspectos aprendidos mais citados pelos participantes

\begin{tabular}{cc} 
Aspecto & Ocorrência \\
\hline Planetas & 127 \\
\hline Sol & 12 \\
\hline Sistema Solar & 10 \\
\hline Lua & 9 \\
\hline Estrela/constelações & 6 \\
\hline Gelo no espaço & 4 \\
\hline
\end{tabular}

Fonte: Autoria própria (2020).

A maioria das manifestações espontâneas de aprendizagem mencionadas pelos participantes versou sobre aspectos relacionados à origem dos nomes, tamanho e composição dos planetas, sobre o Sol e a Lua e sobre o que há nos planetas como crateras, tempestades e anéis. As respostas dos alunos variaram bastante em termos de detalhes. Algumas foram mais curtas, outras mais detalhadas:

"Aprendi sobre o espaço, planetas e estrelas." 
"Eu aprendi que tem planetas que possuem anéis, e que os anéis são compostos de pedras, gás e poeira."

"Aprendi tudo sobre os planetas."

"Aprendi que alguns pontinhos parecendo estrelas eram 5 planetas diferentes."

"Eu aprendi que a terra é o único planeta que tem vida."

"Plutão já foi planeta e não é mais."

"Eu conheci melhor os planetas do Sistema Solar."

Houve quatro alunos que disseram não ter aprendido nada e três alunos não responderam. Além disso, houve três respostas nas quais os alunos revelam certa confusão e/ou a permanência de concepções inadequadas como:

\footnotetext{
"O Sol é um planeta, o maior planeta e o mais quente."

"Aprendi que Mercúrio é o maior planeta do Sistema Solar."; "Que o Sistema Solar é composto de planetas, estrelas, asteroides, meteoros etc."
}

Essas respostas ilustram o fato de que os conteúdos de Astronomia devem ser continuamente trabalhados na educação básica e que a atividade no planetário deve ser integrada às atividades diversas para minimizar os riscos da permanência de concepções em dissonância com o conhecimento científico.

\section{CONSIDERAÇÕES FINAIS}

Este trabalho faz parte de um projeto mais amplo, que contempla ensino/extensão/pesquisa que visa à divulgação científica e a determinar as aprendizagens decorrentes de intervenções pedagógicas realizadas com o planetário, com o intuito de promover o ensino de Astronomia. Como parte inicial deste projeto, buscou-se avaliar o contato prévio, as concepções de Astronomia de alunos do Ensino Fundamental e, após a atividade, verificar a aceitação das estratégias utilizadas e identificar manifestações espontâneas de aprendizagem.

Os resultados obtidos corroboram a expectativa de que o planetário se constitui como um espaço não formal de educação com grande potencial para a divulgação científica e para o ensino de Astronomia. Os alunos, de forma geral, ficaram fascinados durante toda a sessão de cúpula, participando ativamente com perguntas e comentários, demonstrando bastante interesse nos temas abordados. Os alunos se divertiram olhando os "desenhos" das constelações, procurando sempre por estrelas e planetas, pela Lua e pelo Sol. Durante a exibição do filme, alguns imaginaram estar em uma nave espacial, explorando os detalhes do Sistema Solar. Muitos alunos afirmaram que a atividade desenvolvida foi diferente de tudo que já fizeram na escola, que aprenderam muito e se divertiram ao mesmo tempo.

Os alunos apresentaram concepções variadas sobre Astronomia. A grande maioria conseguiu citar palavras diretamente relacionadas ao tema. Os alunos participantes também afirmaram, no geral, que já observaram corpos celestes no céu, como as estrelas e a Lua. O índice de aprovação da sessão de cúpula foi superior a $98 \%$ e quase todos os alunos conseguiram citar algo de novo que aprenderam com a atividade.

Atividades que melhorem a compreensão de crianças e jovens sobre Astronomia devem ser incentivadas e fazerem conexões com fenômenos do mundo real. Não se está afirmando que uma única atividade no planetário seja 
suficiente para mudanças radicais na compreensão dos participantes. Em vez disso, uma visita ao planetário deve ser parte integrante do currículo de Ciências, com conexões feitas entre a experiência com o planetário e o conteúdo abordado e as atividades realizadas em sala de aula, para uma compreensão mais adequada sobre os conceitos astronômicos.

O estudo revelou que cerca de $5 \%$ dos participantes nunca observaram o céu noturno e cerca de $85 \%$ nunca viram um programa ou filme relacionados à Astronomia. Passa-se então a questionar o interesse, normalmente atribuído, de estudantes por Astronomia. Mais pesquisas são necessárias para buscar identificar melhor se há realmente um interesse maior pela Astronomia e se isto resulta em atitudes positivas em relação ao tema (busca por informações, compra de livros sobre o tema, observações etc.).

A atividade extensionista também é rica em experiências para os bolsistas, alunos do curso de Física. Conforme afirma Coelho (2014, p.16),

certas habilidades adquiridas na extensão não são usualmente assimiladas na
experiência do ensino formal (por meio de disciplinas), tais como: capacidade
de interagir e organizar o trabalho em equipes (especialmente as
multidisciplinares); saber ouvir e saber comunicar diante de públicos diversos
e diferentes daqueles que circulam no meio acadêmico.

Considera-se fundamental a introdução das discussões sobre os processos de ensino e aprendizagem desenvolvidos em espaços não formais como o planetário nos cursos de licenciatura de Ciências da Natureza, contribuindo para o desenvolvimento de atividades e metodologias que promovam a interação entre escola e esses novos ambientes de ensino. A extensão universitária constitui-se em uma ferramenta articuladora, alimentando o ensino e a pesquisa, oportuniza ao futuro professor a experiência prática em situações concretas do cotidiano, tornando-o um profissional muito mais comprometido e vinculado com as questões sociais (MORAES; WISNIEWSKI; ROCHA, 2014).

Apesar dos resultados encorajadores, mais pesquisas, com o desenvolvimento de novas abordagens e com diferentes públicos, são necessárias para ampliar nossos conhecimentos sobre a contribuição dos planetários como espaços não formais de educação para a divulgação e promoção do ensino de Ciências e de Astronomia. 


\title{
Astronomy's popularization in the elementary school with a mobile planetarium
}

\begin{abstract}
This paper presents the results of a research whose objective is to analyze and discuss the previous contact and the knowledge about Astronomy of students from schools in Minas Gerais and to evaluate the learning outcomes from dome sessions with a mobile planetarium. The activities described here were developed as part of an extension project. This project aims to disseminate scientific content in astronomy. Two questionnaires were applied before and after the dome session. The results suggest that the extension activity performed was successful, with an accepting rate of over $98 \%$ and with more than $93 \%$ of participants correctly writing something they learned from it. Based on the results, we discuss the educational implications and propose new research possibilities in the area. KEYWORDS: Planetarium. University extension. Non-formal education.
\end{abstract}




\section{AGRADECIMENTOS}

À FAPEMIG pelo apoio financeiro.

\section{REFERÊNCIAS}

ALMEIDA, G. O. et al. O planetário como ambiente não formal para o ensino sobre o sistema solar. Revista Latino-Americana de Educação em Astronomia, n. 23, p. 67-86, 2017.

ARRIGONE, G. M.; MUTTI, C. N. Uso das experiências de cátedra no ensino de física. Caderno Brasileiro de Ensino de Física, v. 28, n. 1, p. 60-90, 2011.

BAILEY, J. M.; SLATER, T. F. A review of astronomy education research. Astronomy Education Review, v. 2, n. 2, p. 20-45, 2003.

BRASIL. Ministério da Educação. Conselho Nacional de Educação. Câmara de Educação Superior. Resolução № 7. Diário Oficial da União, Brasília, 19 de dezembro de 2018, Seção 1, p.49-50, 2018a.

BRASIL. Ministério da Educação. Governo Federal. Base Nacional Comum Curricular. Disponível em: http://basenacionalcomum.mec.gov.br. Acesso em: 13 dez. 2019, 2018b.

BUENO, W. C. B. Jornalismo científico: revisitando o conceito. In: VICTOR, C.; CALDAS, G.; BORTOLIERO, S. (Org.). Jornalismo científico e desenvolvimento sustentável. São Paulo: All Print, p.157-78, 2009.

BUENO, W. C. Comunicação científica e divulgação científica: aproximações e rupturas conceituais. Informação \& Informação, v. 15, n. 1esp, p. 1-12, 2010.

CANIATO, R. Projeto Brasileiro para o Ensino de Física. 1974. 586 f. Tese

(Doutorado em Física) - Universidade Estadual Paulista, Rio Claro, 1974.

CARVALHO, C. L. et al. Um estudo sobre o interesse e o contato de alunos do Ensino Médio com Astronomia. Revista Areté - Revista Amazônica de Ensino de Ciências, v. 9, n. 18, 214-228, 2016.

COELHO, G. C. O papel pedagógico da Extensão Universitária. Em Extensão, v. 13, n. 2, p. 11-24, 2014.

COSTA, P. M. D.; SANTOS, S. R. M.; GRINSPUN, M. P. S. Z. Extensão Universitária e o Campo da Política Cultural. Meta: Avaliação. v. 1, n. 3, p. 369-385, 2009.

DE MAMAN, A. S. et al. Planetário Móvel: Divulgação científica em um espaço de ensino não formal. ENCONTRO NACIONAL DE PESQUISA EM EDUCAÇÃO EM CIÊNCIAS, X, 2015. Águas de Lindóia. Atas... Porto Alegre: ABRAPEC, 2015. 
DONOVAN, M. S.; BRANSFORD, J. D. Scientific Inquiry and How People Learn. In: NRC. How Students Learn: Science in the Classroom. Washington, DC: The National Academies Press, p. 397-419, 2005.

ELIAS, D. C. N.; AMARAL, L. H.; ARAÚJO, M. S. T. Criação de um espaço de aprendizagem significativa no planetário do parque Ibirapuera. Revista Brasileira de Pesquisa em Educação em Ciências, v. 7, n. 1, p.1-15, 2007.

FREITAS, R. A.; GERMANO, A. S. M.; AROCA, S. C. Um estudo das pesquisas em ensino e divulgação de astronomia em espaços não formais de educação no Brasil. ENCONTRO NACIONAL DE PESQUISA EM EDUCAÇÃO EM CIÊNCIAS, IX, 2013, Águas de Lindóia. Atas... Porto Alegre: ABRAPEC, 2013.

GOMES, B. C. C.; ZANON, D. A. V. . A educação através da Ciência, Tecnologia e Sociedade (CTS) para os anos iniciais do Ensino Fundamental: a Terra e o Universo em foco. ACTIO, v. 4, p. 146-164, 2019.

HEIMLICH, J. E; SICKLER, J.; YOCEO, V.; STORKSDIECK, M. Influence of Immersion on Visitor Learning: Maya Skies Research Report. 2010. Disponível em http://www.informalscience.org/influence-immersion-visitor-learning-mayaskies-research-report. Acesso em: 25 jul. 2019.

LANGHI, R. Astronomia nos anos iniciais do Ensino Fundamental: repensando a formação de professores. 2009. 370 f. Tese (Doutorado em Educação para a Ciência). Faculdade de Ciências, UNESP, Bauru, 2009.

LANGHI, R. Educação em Astronomia: da revisão bibliográfica sobre concepções alternativas à necessidade de uma ação nacional. Caderno Brasileiro de Ensino de Física, v.28, n.2, p. 373-399, 2011.

LANGHI, R.; NARDI, R. Ensino da Astronomia no Brasil: educação formal, informal, não formal e divulgação científica. Revista Brasileira de Ensino de Física, v.31, n.4, p. 4402, 2009.

LANTZ, E. Planetarium of the Future. Curator: The Museum Journal, v. 54, n. 3, p. 293-312, 2011.

LELLIOTT, A.; ROLLNICK, M. Big Ideas: A review of astronomy education research 1974-2008. International Journal of Science Education, 32 (13), p.1771-1799, 2010.

LOPES, A. O. Aula Expositiva: Superando o Tradicional. In: VEIGA, I. P. A (org.). Técnicas de Ensino: Por que não? São Paulo: Papirus, 1991.

LOUREIRO, J. M. M. Museu de ciência, divulgação científica e hegemonia. Revista Ciência da Informação, v. 32, n. 1, p. 88-95, 2003.

MARANDINO, M. et al. A educação não formal e a divulgação científica: o que pensa quem faz? In: Moreira, M. A. ENCONTRO NACIONAL DE PESQUISA EM 
MILONE, A. C; WUENSCHE, C. A; RODRIGUES, C. V; JABLONSKI, F. J; CAPELATO, H. V; VILAS-BOAS, J. W; CECATTO, J. R; NETO, T. V. Introdução a astronomia e astrofísica. Instituto Nacional de Pesquisas Espaciais - INPE, São José dos Campos, 2003. Disponível em:

http://staff.on.br/maia/Intr_Astron_eAstrof_Curso_do_INPE.pdf. Acesso em: 25 jul. 2019.

MORAES, S. R.; WISNIEWSKI, G.; ROCHA, J. R. C. "Ciência na praça”: a faculdade interagindo com a comunidade. Holos, v. 4, p. 463-472, 2014.

ROMANZINI, J.; BER, A. R. Planetário de Londrina: cinco anos de atividades para a divulgação e popularização da Astronomia. SIMPÓSIO NACIONAL DE EDUCAÇÃO EM ASTRONOMIA, II, 2012. São Paulo. Atas... São Paulo: SBA, 2012.

SANTOS, A. H.; MACHADO, S. M. F.; SOBRAL, M. N. Temas Geradores no Ensino de Química: Concepções de educadores e educandos de duas escolas da Rede Estadual de Ensino Básico de Sergipe. Revista Teias, v. 17, n. 44, p. 206-222, 2016.

SIEMSEN, G. H.; LORENZETTI, L. A Pesquisa em Ensino de Astronomia para o Ensino Médio. ACTIO, v. 2, n. 3, p. 185-207, 2017.

SÍVERES, L. A extensão como um princípio de aprendizagem. Revista Diálogos, v. 10, p. 8-17, 2010.

SLATER, E. V.; MORRIS, J. E.; MCKINNON, D. Astronomy alternative conceptions in pre-adolescent students in Western Australia. International Journal of Science Education, v. 40, n. 17, p. 2158-2180, 2018.

SOLER, D. R.; LEITE, C. Importância e Justificativas para o Ensino de Astronomia: um olhar para as pesquisas da área. Simpósio Nacional de Educação em Astronomia, II, 2012. São Paulo, Atas..., 2012.

SPECHT, C. C.; RIBEIRO, M. E. M.; RAMOS, M. G. Estudo da Complexidade de Abordagens Envolvendo Perguntas Formuladas por Estudantes e Professores em Aulas de Química na Educação Básica. Revista Debates em Ensino de Química, v. 3, n. 2 ESP, p. 19-33, 2017.

TÜRK, C.; KALKAN, H. The effect of planetariums on teaching specific astronomy concepts. Journal of Science Education and Technology, v. 24, n. 1, p. 1-15, 2015.

VIEIRA, V.; BIANCONI, M. L.; DIAS, M. Espaços não-formais de ensino e o currículo de ciências. Ciência e Cultura, v. 57, n. 4, p. 21-23, 2005.

VILAÇA, J.; LANGHI, R.; NARDI, R. Planetários enquanto espaços formais/não formais de ensino, pesquisa e formação de professores. ENCONTRO NACIONAL DE PESQUISA EM EDUCAÇÃO EM CIÊNCIAS, IX, 2013. Águas de Lindóia. Atas... Porto Alegre: ABRAPEC, 2013. 
Recebido: 17 jun. 2020

Aprovado: 29 out. 2020

DOI: $10.3895 /$ actio.v5n3.11600

\section{Como citar:}

MELO, J. P. da S.; OLIVEIRA, S. W. de P.; GOMES, A. D. T.; COELHO, F. O. Divulgando astronomia no ensino fundamental por meio de um planetário móvel. ACTIO, Curitiba, v. 5, n. 3, p. 1-21, set./dez. 2020. Disponível em: <https://periodicos.utfpr.edu.br/actio>. Acesso em: XXX

Correspondência:

João Paulo da Silva Melo

Praça Dom Helvécio, 74 Sala A 2.06 DCNAT. Fábricas, São João del-Rei, Minas Gerais, Brasil.

Direito autoral: Este artigo está licenciado sob os termos da Licença Creative Commons-Atribuição 4.0

Internacional.

(c) (1) 